\title{
RIO ACIMA: PERCURSOS PELO FILME APOCALIPSE NOW
}

\author{
Wencesláo Machado de Oliveira Jr"
}

\section{Os homens}

Horrível. Sim, era bastante horrendo, mas, desde que se tivesse suficiente coragem, acabava-se admitindo a existência dentro de si mesmo de um vago impulso para responder à terrível espontaneidade daquele alarido, à obscura impressão de haver naquilo um sentido que você - tão distante na noite dos tempos não podia compreender. A mente do homem é capaz de tudo, pois nela tudo se encontra, todo o passado assim como todo o futuro. O que havia lá, afinal? Alegria, medo, dor, devoção, bravura, ódio, quem saberia dizer? A verdade, em todo o caso, a verdade despojada do manto do tempo. Que o tolo se embasbaque e estremeça... o homem compreende e pode olhar de frente sem pestanejar. (Conrad, O coração da treva, p. 58).

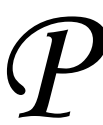

enetrar. Este é o verbo que fica desta narrativa. As câmeras do filme descrevem a viagem em direção ao interior da floresta através do rio. As palavras do narrador-personagem nos inserem na viagem que ele faz rumo ao seu próprio interior. Não há uma cisão nestes dois percursos, eles são o mesmo: câmeras e palavras apresentam o homem a caminho...

Nas telas, dois homens protagonizam a penetração: Kurtz e Wilard. O segundo refaz a trilha do primeiro; começou alguns passos (anos?) adiante, terminará alguns passos depois...

Fora das telas há também dois homens que protagonizam uma outra (a mesma?) investida: Coppola e o espectador. Também o segundo persegue os passos do primeiro, mas já não há semelhança ou relação temporal entre os dois: o que os liga é o percurso. O primeiro, o diretor, viveu o mundo do cinema; o segundo, eu mesmo, vivo o mundo do

Professor no Departamento de Metodologia do Ensino da Faculdade de Educação (FE/Unicamp) e pesquisador do Laboratório de Estudos Audiovisuais - OlHo (FE/Unicamp). 
filme. No entanto, há entre estes dois homens uma relação íntima que se concretiza na ficção da obra e de suas personagens principais. Através destas últimas, ou talvez de apenas uma delas, Wilard, deixamos de ser muitos para nos tornar um só, o homem. Assim, corporificados num único ser (que é todos e nenhum), é que fazemos juntos a mesma viagem. Nela, o viajante segue passos já dados...

O percurso pioneiro, de Kurtz (ou seria de Conrad?), nos é (dado conhecer) apresentado pelas reflexões de Wilard e pelos olhos das câmeras, quando estes coincidem com os de Wilard. São fragmentos, memórias esparsas da trajetória de um homem que foi ao fundo de suas ambições e crenças, que levou ao extremo as táticas de guerra e a devoção à pátria, mas que se deparou com uma força maior que brotava da terra, da floresta, das tradiçõos, do fundo do mundo. Ele não resistiu a ela, resistindo ao mundo. É nela que ele já se embala quando o filme começa.

No hotel, Wilard recebe a missão de destruir um homem, Kurtz, que aos poucos reconhecerá como superior. Ao penetrar cada vez mais na floresta (na guerra), no coração do território-chão-terra (no coração do homem-louco-santo), ele vai descortinando o poder do mundo, o poder de deuses. Assim como os homens da floresta, ele passa a adorar Kurtz. Passa a adorá-lo mais até que estes, pois o enxerga como o homem-forte do seu mundo americano e racionalizado, ao mesmo tempo que como o homem-templo de um mundo primitivo e telúrico no qual ele penetra aos poucos.

Ao final, ele se fundirá ao homem de pedra cujo tempo se perde nas nossas origens. As imagens na tela fundem, com lentidão, o rosto de carne de Wilard com a face de pedra de um totem pagão; no entanto, é como se entre eles existisse uma leve distância, um véu, uma fina película...

Em seu corpo-memória Wilard tira Kurtz, o ídolo de pedra, da floresta para a cidade, do passado para o futuro, do coração para todas as partes do corpo-terra. Das trevas para a luz... artificial: holofotes, flashes, projetores.

\section{Os corações}

Nessa época havia muitos espaços vazios sobre a Terra e, quando deparava no mapa com algum deles que se mostrasse particularmente atraente (todos, na verdade, se mostram assim) colocava o dedo sobre ele e dizia: 'Quando crescer irei até ai'.(...) Havia um deles, porém - o maior de todos e, por assim dizer, o 
mais deserto - pelo qual eu sentia poderosa atração. Em realidade, já não era nessa época um espaço branco. Fora preenchido, desde minha infância, com rios, lagos e nomes. Deixara de ser a delimitação de um vazio prenhe de deliciosos mistérios - alva mancha sobre a qual um menino poderia projetar seus sonhos de glória. Tornara-se um lugar de trevas. (Conrad, O coração da treva, p. 16).

O coração não está no centro de um corpo. Nem é o seu centro único de energia. Ele é tão somente uma mola: sua maior grandeza é pulsar, ou melhor dizendo, explodir e expulsar o que nele penetra para o mais distante possível. As marcas deixadas por esta passagem, por esta explosão, são marcas infinitas... eternas. A atração para um retorno é brutal. E ele sempre torna a ocorrer. O coração não se permite o vazio ou a paz...

Na metáfora geográfica o coração transforma-se em centro. Ele é e está no meio, compõe o miolo, o âmago, o lugar de maior penetração. Carrega consigo a idéia de maior densidade e escuridão. É a expedição a este centro geográfico-florestal que o filme mostra. Não importa ali o lugar real. Na novela de Conrad, a história se passa no Congo, no cinema de Coppola ela se desloca para as Filipinas. No filme Apocalipse now ela desenrola-se no Vietnã. Houve um deslocamento no espaço real-concreto para preservar o lugar ficcional.

A forma de apresentação da história foi atualizada: do romanceconto para o cinema-filme. Também o tema foi deslocado no tempo: da colonização novecentista do Congo Belga para a guerra imperialista do Vietnã e daí para as filmagens nas Filipinas em plena guerra civil. Não importa qual ação civilizatória do homem esteja em questão, o que é enfocado é o seu equívoco, a sua loucura.

Apenas uma das ações apocalípticas que giram em torno desta saga teve o final desejado e, podemos assim dizer, feliz: a do cinema. A insanidade do mergulho de Coppola se revelou num belíssimo filme e num sucesso de público e de crítica, e de política. Também quanto ao cinema, como artefato-arte, podemos dizer isto: sua ação civilizatória, durante o século XX, é um sucesso de público, de crítica e de política!

Não podemos dizer o mesmo quando pensamos nos desastrosos resultados da colonização da África Central ou das guerras na Península do Indostão...

“A melhor explicação que posso dar a vocês é que, por um ou dois segundos, senti-me como se estivesse indo não para o âmago de um continente mas para o centro da Terra" (Conrad, O coração da treva, p. 
23). Esta é a frase de Marlow, o personagem conradiano tornado Wilard no filme de Coppola. Carregado de emoção, ele conta aos seus companheiros a reação que teve logo após assinar o contrato para comandar um barco no coração da selva africana.

É interessante notar que, geologicamente falando, a África é o centro das terras (emersas) do planeta. Este continente é o único que permanece parado, estável, desde a formação do primeiro grande bloco rochoso, o Gondwana. Foi deste bloco original que se desmembraram as atuais terras que formam os outros continentes: Antártida, Eurásia, Américas e Oceania. A África está grosseiramente eqüidistante das outras quatro massas continentais que, sob um certo ponto de vista, se originaram dela e se deslocaram em direções opostas.

Mas não era a este centro que, metaforicamente, Conrad se referia. Era o do calor, das quantidades magmáticas que geraram e geram ainda as rochas e as tochas vulcânicas do planeta. Lugar desconhecido, misterioso em sua particularidade de origem material de todos nós. Fogo. Coisa informe em cujo seio todas as formas existentes e outras mil já existiam como potência. No meio do mundo é onde tudo há, e onde tudo e todos podem.

Além desta possibilidade metafórica, este autor poderia estar se referindo à posição central que a colonização do continente africano ocupava nos corações e mentes dos "homens civilizados" da época. A empresa colonizadora em todas as suas facetas, desde as mais ingênuas crenças na cristianização total e pacífica dos negros até a usurpação dos territórios e riquezas em nome de um uso mais racional destes meios, envolveu uma grande quantidade de homens e idéias que, emprestando a sua força e coragem - seu poder de matar e persuadir - ligou as populações e regiões africanas às cidades industriais européias. A civilização dos "povos bárbaros" foi a grande "boa ação" que os ideais humanistas realizaram nos finais do século XIX. Isto deixava os europeus na posição de gentis senhores que ajudam a erradicar o mal, o demônio, as sombras, do resto do mundo.

Coppola, ao transferir o cenário para o Vietnã, atualizou esta falácia. Os Estados Unidos, grande país guardião do bem e da democracia do final do século XX, invadem um território que não lhes pertence. Os soldados americanos sentiam-se como os europeus colonizadores, só que não mais como homens que levam a civilização e eliminam a barbárie, mas como protetores desta ordem já estabelecida, garantidores do mundo civilizado e monetarista. 
A ironia de Conrad, intensificada por Coppola nas telas, põe a nu o desconhecimento e a tensão com que se travaram estas batalhas, a coragem com que certos homens ficaram face a face com o contato impossível. Mais, esfrega em nossas caras o efeito devastador sobre o homem da descoberta de sua própria superioridade e magia sobre os outros. Kurtz descobre-se na posição de deus, aceita e renega tal lugar na hierarquia, mas se fascina com tal poder. Dita e desdita ordens. No filme, escolhe a hora da sua morte. Morte sacrificial.

No escuro da floresta é que se imola o corpo. O imenso silêncio das matas afoga os gritos, distancia o distante, redime os seus criminosos. O silêncio é sua mais poderosa arma. É nele que ela, a floresta, se esconde e trama. É no coração da selva que o esquecimento se dá. É onde ele fica à espreita, é de onde parte em suas investidas. Assimila tudo e vai desfazendo tudo que nele penetra, transformando em lodo, nódoa, húmus fértil... Aquele que sobrevive torna-se outro. Se domina a treva, torna-se seu rei e imperador. Ela se curva, perde a rebeldia.

Mas a dominação total - a obediência total - é a loucura. A floresta protege seu dono; mas não só a ele ela se oferece protetora. Está aberta para aquele que tiver a coragem (ou a inocência) de penetrá-la, de impor sua força diante de seus profundos mistérios. É este o "herói” silencioso ou do silêncio. Ele entra e vai em busca... percorre caminhos em direção à chave, ao encontro. Lutará pela escuridão adentro e, ao encontrar o clarão de algum Kurtz, se deslumbrará com sua riqueza e onipotência. Wilard foi libertar a guerra dos desígnios de um homem que a floresta protegia. Terminou por libertar este mesmo homem das forças florestais primitivas.

$\mathrm{O}$ vencedor é eleito sucessor. Wilard não aceita tal posto. Segue viagem. No entanto, ele não irá voltar para o seu antigo lugar, a sua primeira civilização. Ele já não mais pertence a ela... Desliga o rádio, seu contato com o seu ex-mundo e permite-se escutar o silêncio absoluto da floresta.

No barco, o único sobrevivente junto a Wilard neste retorno impossível é o surfista. Ele foi o primeiro a descobrir a face da selva. Inocente, ele transforma o seu rosto em cara nova, pinta-a e se protege. Salva-se pela singeleza infantil que, de modo algum, exclui a crueldade e a astúcia de réptil.

$\mathrm{Na}$ margem, na platéia, a multidão prende a respiração. Uma vez morto seu comandante, desamparado em seu vazio, o coração da treva simplesmente fecha-se em seu silêncio inicial. Estará à espera de um novo duelo... de um novo deus... de um novo esquecimento. 
Apocalipse now é a história de homens saturados. Homens transbordando conquistas. Este já era o eixo da historia que Conrad contou. A viagem do Kurtz para a África deveu-se ao casamento, mas ele se embrenhou na mata à caça de marfim. O Capitão Kurtz se envolveu na guerra em busca da vitória americana, mas se envolveu com a Guerra. Por trás deles está o (deslocamento do) ideal; é ele que pulsa, encoraja, bate, conquista, se nutre, transborda, expia...

Assistimos à história de vencedores que perderam.

Os dois foram capturados em seus percursos, tornando-se tão intrinsecamente ligados aos mundos onde lutavam que não mais se viam fora deles. Viraram produto daquela terra. Era dela a matéria que passou a constituir seu corpo, de tanto ali aspirar o ar, pisar e roçar aquele chão. De tanto ali olhar e ver aquele desencontro - aquela outra humanidade - as imagens do mundo de onde vieram foram tornando-se baças, bobas, gastas. Aos poucos a imaginação destes homens tornou-se prisioneira de um novo mundo, deslocado daquele primeiro, onde as imagens projetadas em suas mentes viraram pedra, marfim e guerra. Eles penetraram com seus olhos as cenas que encharcaram seus corações e explodiram as antigas amarras, ocupando-os para sempre... Era preciso morrer ali. E outro personagem, Odradek, de outra história, é quem pergunta: "Será que pode morrer?"; e ele mesmo dá a resposta: “Tudo o que morre teve antes uma espécie de meta, um tipo de atividade e nela se desgastou" (Kafka, "A preocupação do pai de família", in: Um médico rural, p. 42).

O coração daqueles homens encontrava-se abarrotado, já havia encontrado a paz... o horror.

As águas

Havia no entanto, ali, um rio em especial - Um grande e portentoso rio que se podia ver no mapa semelhante a uma imensa serpente desenrodilhada: a cabeça no mar, o corpo em repouso ziguezagueando ao longo de um vasto território e a cauda perdendo-se nas profundezas do interior. (Conrad, O coração da treva, p. 16).

O mergulho que fazemos no filme é total. Tempo-espaço-homem. Tudo que é material se desmaterializa, se assim o quisermos. O rio pode ser estrada, a guerra pode ser angústia, a floresta pode ser treva... e podem ser também, e ao mesmo tempo, tão somente um rio, uma guerra, uma floresta... 
O que nos faz penetrar neste (nosso) mundo? O trivial, talvez. No filme, a penetração no rio se dá por um destes motivos banais: surfar. $\mathrm{O}$ acaso age solto, nada é coincidência. Há um surfista na "comitiva" de Wilard. O comandante do batalhão de helicópteros admira muito a este surfista; quer fazer algo pelo seu ídolo. Então bombardeia a aldeia, enquanto surfam as ondas. $\mathrm{O}$ barco e seus tripulantes são lançados na boca do rio-abismo porque o comandante queria surfar naquela desembocadura! As ondas do mar é que os levaram para dentro da floresta. É como se o oceano (a Marinha) avançasse sobre as águas do rio.

Neste filme, o que vemos na tela não é tão somente a subida de um rio por um barco de guerra. O rio que acompanhamos é a penetração de um homem em sua escuridão. É uma versão moderna e misturada de dois Ulisses: o de Homero, em sua saga geográfica, e o de Joyce, em sua viagem interior. Destino: um lugar geográfico bem definido e uma incerta origem e continuidade.

Wilard navega sobre o rio após ter penetrado na serpente. Ele está em seu ventre. É de lá que ele ressurgirá quando aportar em terra: como cobra, misto de gente e víbora. A pintura no rosto de Kurtz e de Wilard - e do surfista - lembra escamas répteis. Os próprios movimentos são lentos e solitários; preparam e dão o bote.

Pelo rio acima, pela floresta adentro, o herói vai sorvendo o veneno da guerra, e vai tendo alucinações de festas e bombardeios, cujos resultados cênicos são de extrema semelhança: espetáculos pirotécnicos de iluminação intensa perante aquele fundo negro e trevoso. Wilard vai recolhendo as suas fagulhas, as suas clarividências quanto ao conhecimento do homem, para que ele possa se aproximar dele, do homem que ele busca: Kurtz. E ele só o encontraria se chegasse ao limite, se atravessasse o limiar.

O marinheiro Marlow, narrador e protagonista desta saga na novela conradiana, diz que o acampamento de Kurtz

era o ponto extremo acessível à navegação; foi também o ponto extremo de minha aventura. Parecia, de alguma forma, espalhar uma espécie de luz sobre as coisas à minha volta e em meus pensamentos. Era muito sombrio também e lamentável - nada de extraordinário, contudo - e não muito inteligível. Não, não muito inteligível. E, mesmo assim, parecia espargir uma espécie de luz... (Conrad, $O$ coração da treva, p. 15).

Não é possível ao homem navegar à nascente de onde brota o olho d'água, onde terra e água criam a corrente. Há um limite, e é neste 
limite que as escadarias de Kurtz encontravam-se. Dali para frente era entrar sobre os dois pés, era se deixar tocar pela proximidade do início, de algum começo não permitido aos olhos. E nesta escuridão primordial que o homem tem que entrar sozinho - onde ele tem que deixar seu barco na margem - que Kurtz penetrou. Ele ultrapassou muito o limiar, mergulhou na corrente onde ela se criava... Daí a luz, brilho primordial. Revelação, apocalipse.

Wilard chega onde está Kurtz, mas não continuou a viagem rio acima. Solta o seu barco e deixa que ele desça o rio; segue as forças da (sua) natureza, pára de lutar com elas. Antes disso, pinta seu rosto como Kurtz se havia pintado. Só então mata-o. Ao executar Kurtz, Wilard torna-se enviado de suas angústias, de suas memórias; apropria o conhecimento deste homem que passa a ser ele mesmo. No momento em que Wilard aceita imolar Kurtz, eles se irmanam, se penetram, um se realizando no outro: Wilard morre com Kurtz, Kurtz se salva e volta com Wilard. Quem solta o barco e desce o rio são os dois...

Chuvas passageiras atravessam o percurso do barco. $\mathrm{O}$ mundo tropical se faz pleno nestas gotas que completam o cerco das águas. Chuvas que enchem os rios e tornam mais poderosa a contra-corrente, mais necessário o esforço...

Marlow relata apenas neblina, umidade. Coppola mantém-se fiel a Conrad: muita neblina, muita umidade a envolver esses homens que penetram no mundo aquoso da floresta virgem.

Ao final da subida do rio, as águas de cima se fazem mais presentes. Não são elas despejadas pelos céus, mas pedidas pelos homens. Vêm aumentar a opacidade, montar, de toda aquela multiplicidade, um mundo só; vêm tornar a terra lodo, lama... barro.

No clímax deste filme a chuva se impõe. Permanece.

Ao contato do barco trazendo Wilard na margem do rio, ao pé das escadas que o levariam a Kurtz, a atmosfera daquele inferno úmido se condensa... em gotas que fazem chover: a chuva da chegada é também passagem ritual. Wilard e os outros ficam de frente para o templo de Kurtz. A chuva vem lavar os rostos e as imagens; vem desprendê-los do percurso e grudá-los à presença todo poderosa de Kurtz. Este homem deixará, então, de ser uma sombra fotografada para se tornar matériaforça: sua cabeça imensa e lisa, suas mãos e sua voz.

Há uma última chuva. A chuva da partida. Ela cai quando Wilard atravessa em meio aos fiéis guerreiros de Kurtz e volta ao seu barco: porto mais seguro. Esta chuva cai no final da projeção. Ela não cai na 
floresta, cai no cinema. Não faz parte do mundo primordial que a floresta esconde e conserva, mas da urbanidade que a penetrou. É a cidadecinema que faz cair a chuva. A floresta se apropria dela, a retoma da urbanidade para levar (escorrer) o mundo do barco-cidade para o barcocidade do mundo. É uma chuva infinita, é som em nossos ouvidos, desprega-se da tela e cai ao nosso redor, molhando nossos rostos (meu rosto!) com constatações terríveis. Ela é o barulho do destino nos carregando rio abaixo...

Referências bibliográficas

ALMEIDA, Milton José de. Anotações para o estudo da linguagem das imagens e sons na cultura atual. Texto mimeografado apresentado no Congresso de Ensino de História, São Paulo, USP, 1996.

CONRAD, Joseph. O coraşão da treva. São Paulo: Global, 1984.

KAFKA, Franz. Um médico rural. São Paulo: Brasiliense, 1990.

MARTIN, Marcel. A linguagem cinematográfica. São Paulo: Brasiliense, 1990.

PASOLINI, Pier Paolo. Empirismo herege. Lisboa: Assírio Alvim, 1982.

Filmografia

COPPOLA, Francis Ford. Apocalipse now. Estados Unidos, 1979.

COPPOLA, Eleanor; COPPOLA, Francis Ford. $O$ apocalipse de um cineasta. Estados Unidos, 1991. 